\title{
Speciation and antifungal susceptibility testing of candida species isolated from clinical samples
}

\author{
Lokjan Singh', Sheetal U Harakuni ${ }^{2}$, Bibek Basnet ${ }^{3}$, Keshab Parajuli $^{4}$ \\ ${ }^{1}$ Post Graduate Student, ${ }^{2}$ Professor, Department of Microbiology, KLE Academy of Higher Education and Research, \\ Jawaharlal Nehru Medical College, Belagavi, Karnataka, India, ${ }^{3}$ Post Graduate Student, Department of Biochemistry, \\ KLE Academy of Higher Education and Research, Jawaharlal Nehru Medical College, Belagavi, Karnataka, India, \\ ${ }^{4}$ Lecturer, Department of Public Health, Asian College for Advance Studies, Purbanchal University, Nepal
}

Background: The importance of epidemiological monitoring of yeasts involved in pathogenic processes is unquestionable due to the increase in trend of infections caused by various species of Candida over the last decade; so are the changes observed in species causing Candidiasis and empirical antifungal treatment. Aims and Objective: To speciate the clinically isolated Candida species by phenotypic methods and to estimate the antifungal susceptibility of the isolated species against fluconazole, ketoconazole, voriconazole, itraconazole by disc diffusion method. Materials and Methods: A cross-sectional study conducted in 2018 in the Department of Microbiology, J. N. Medical College, KAHER, Belagavi Karnataka. Ethical Clarence was obtained from institutional ethical committee J.N. Medical College. Results: Out of 59 Candida isolates, Candida tropicalis was the predominant species $41(69.49 \%)$, followed by Candida glabrata 5 (8.47\%), Candida parapsilosis and Candida lusitaniae 4 (6.78\%) respectively, Candida guilliermondii and Candida kefyr $2(3.39 \%)$ respectively and the least one was Candida krusei 1 (1.69\%). Voriconazole showed the highest level of sensitivity whereas Itraconazole has shown the least sensitivity pattern by disk diffusion method. Out of 59 Candida species, 52 (88.13\%) were sensitive to Voriconazole, 44 (74.57\%) were sensitive to Fluconazole, 40 (67.79\%) were sensitive to Ketoconazole and the least sensitivity was shown by Itraconazole 30 (50.84\%). Candida krusei and Candida guilliermondii showed 100\% sensitive to Fluconazole, Voriconazole, Ketoconazole and Itraconazole respectively. Conclusion: Non-albicans Candida species are being common isolates from cases of candidiasis. Candida tropicalis is the predominant isolate, followed by Candida glabrata, Candida lusitaniae, Candida parapsilosis, Candida guilliermondii, Candida kefyr and Candida krusei. Most of the isolates were sensitive to Voriconazole.

Key words: Disk diffusion method; NAC; Sensitive; Predominant species
Access this article online Website:

http://nepjol.info/index.php/AJMS

DOI: 10.3126/ajms.v11i4.28494

E-ISSN: 2091-0576

P-ISSN: 2467-9100

Copyright (c) 2020 Asian Journal of Medical Sciences

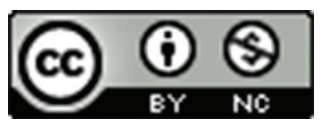

This work is licensed under a Creative Commons Attribution-NonCommercial 4.0 International License.

\section{INTRODUCTION}

Importance of an epidemiological monitoring of yeasts involved in pathogenic processes is unquestionable due to the increase in trend of infections caused by various species of Candida over the last decade; so are the changes observed in species causing Candidiasis and empirical antifungal treatment. ${ }^{1}$ There is a rise in non-albicans Candida species being more prevalent with varied antifungal susceptibility. There is need for continous surveillance of prevailing species and to know their antifungal susceptibility so as to aid in treatment of affected patients ${ }^{2}$. The present study is taken to know the prevalent species isolated from various clinical specimens and their antifungal susceptibility testing by disc diffusion technique aginst various antifungal agents such as fluconazole, ketoconazole, voriconazole and itraconazole.C. albicans is the common and major pathogen considered to cause Candidiasis among Candida species, more frequently the immunocompromised individuals are affected suffering from HIV, using ling-term immunosuppressive therapy in 
cancer and organ transplant patients, Azole resistance were seen more commonly in non-albicans Candida than the Candida albicans, therefore, antifungal susceptibility testing will help to choose the empirical antifungal treatment and to identify to species level; it will also help the epidemiology of Candida species particularly the source and mode of transmission so that we can prevent and control the transmission and resistant pathogens. ${ }^{2-5}$ Over the past 2-3 decades increasing numbers of incidence due to non-albicans Candida species is significant although considered as normal flora of human beings at the different sites such as skin, female genital tract, gastrointestinal tract, respiratory tract etc. Due to variety of predisposing factor it alters the host immune status of the individuals which leads to invasive Candidiasis. Virulence factors of Candida species plays as essential role to facilitate the pathogenesis of Candidiasis such as; Adhesion: that interact with the surface of endothelial and epithelial cells. Enzymes: Phospholipase, Esterase, Proteases, Lipase plays an important role to initiate the infection. Toxins: These are like endotoxin in bacteria which induce the anaphylactic shock, Virulent to the patients such as-glycoproteins. Phenotyping Switching: In which the organisms has the ability to grow in various morphological features such as unicellular budding (blastospore) to filaments pseudo hyphae and sometimes true hyphae which helps the organisms to survive in the host at different conditions or temperature to facilitate the pathogenicity.-9

\section{MATERIALS AND METHODS}

A cross sectional study was conducted at the Department of Microbiology, Jawaharlal Nehru Medical College, Belagavi. In the year 2018 from January 2018 to December 2018, isolates were collected from clinical samples by Universal sampling procedurewhere all theIsolates from patients withInvasive Candidiasis, Suspected cases of Candidiasis were included. Once the isolates of Gram positive yeasts were identified in the sample, the smears of the samples were reviewed by the investigator. The sputum samples were graded by Bartlett's scale. If the sample was graded between' '1' to ' 2 ' the samples were included in the study. The patient's clinical diagnosis was also considered before including the isolate ${ }^{10}$. The vaginal samples' smear was graded as per Nugent's criteria. Score of 7-10 was taken as diagnostic of Bacterial Vaginosis Candida spp. Thus isolated was regarded as co-infector. ${ }^{11}$ Germ tube test is done for presumptive identification of Candida species which differentiate between Candida albicans (positive) from non-albicans Candida species (negative) based on the production of tube like filaments at the point of origin, are not constructed in case of Candida albicans whereas constriction is seen in non-albicans Candida. ${ }^{12}$ Rapid method for cultivation and identification of Candida species. Distinguished between divers Candida species based on morphological features. ${ }^{8,13,14}$ Antifungal susceptibility testing plays an essential role to establish an appropriate antifungal drug to treat specific fungal infection. This was done for all the 59 isolated Candida species, antifungal disc were used from Hi-Media (India), which were commercially prepared. Antifungal susceptibility testing was performed as per CLSI for antifungal (formerly NCCLS) M44-A2 guideline which recommends Muller Hinton Agar, $2 \%$ Glucose with $5 \mu \mathrm{g} / \mathrm{ml}$ Methylene blue. After 48 hours of incubation the zone of inhibition around the disc is measured. ${ }^{3,15,16}$

\section{RESULTS}

In Graph 1, among 59 Candida isolates Candida tropicalis was the predominant species 41(69.49\%), followed by Candida glabrata $5(8.47 \%)$, Candida parapsilosis and Candida lusitaniae $4(6.78 \%)$ respectively, Candida guilliermondii and Candida kefyr $2(3.39 \%)$ respectively and the least one C. krusei $1(1.69 \%)$.

In Table 1, our study out of 59 clinical samples sputum was $28.81 \%$ followed by vaginal swab $27.11 \%$ and the least collected samples cervical swab, Broncho-alveolar lavage and stool were $3.38 \%$ followed by Sub hepatic fluid, oral tissue and skin scrapping were $1.69 \%$.

In Tables 2 and 3, our study Voriconazole showed the highest level of sensitivity whereas Itraconazole had shown the least sensitivity pattern by disk diffusion method. Among all the isolated 59 Candida species, 52 (88.13\%) were sensitive to Voriconazole, $44(74.57 \%)$ were sensitive to Fluconazole, $40(67.79 \%)$ were sensitive to Ketoconazole and the least sensitivity was shown by Itraconazole $30(50.84 \%)$. Among 41 (69.49\%) isolates of Candida tropicalis 37 (90.24\%) were sensitive to Voriconazole, 31 (75.61\%) were sensitive to Fluconazole, $28(68.29 \%)$ were sensitive to Ketoconazole and $22(53.22 \%)$ were sensitive to Itraconazole. Candida krusei and Candida guilliermondii

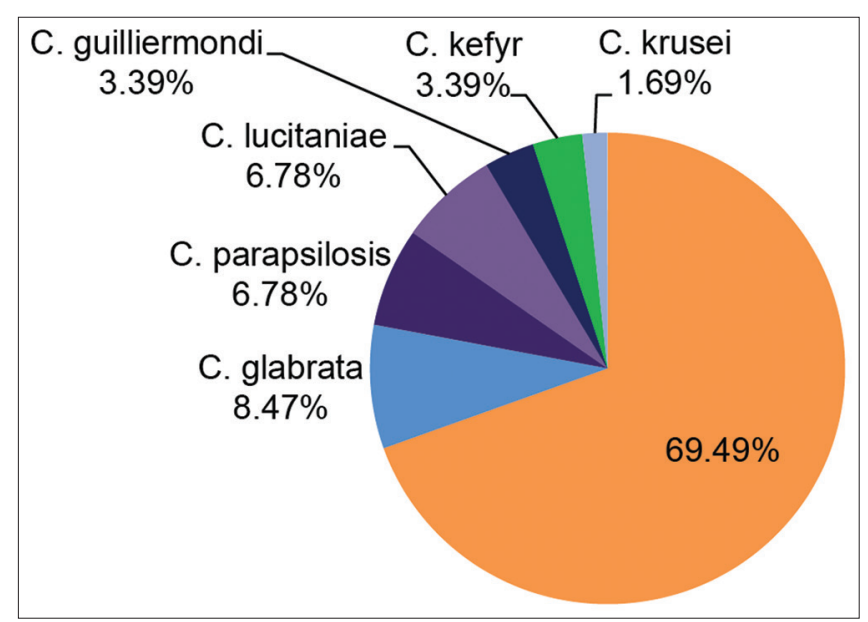

Graph 1: Distribution of isolates in percentage 
showed 100\% sensitive to Fluconazole, Voriconazole, Ketoconazole and Itraconazole respectively.

Figure1 and 2 Antifungal Susceptibility testing.

\section{DISCUSSION}

A total of 59 isolates were processed from the samples received in the Department of Microbiology of Jawaharlal Nehru Medical College, KAHER University, Belagavi. Among isolates Candida tropicalis was found to be the most predominant species whereas Candida krusei is the least to be isolated. In our study Candida tropicalis being the most predominant species $41(69.49 \%)$. Similar studies done by Bhawana et al, ${ }^{3}$ Singh $\mathrm{R}$ et al ${ }^{17}$ have reported Candida tropicalis, ranging between $26-59 \%$, being the major isolate. ${ }^{3,14,17}$

A study carried out by Khadka. S et al ${ }^{18} 2014-15$ Nepal has found that Candida tropicalis is the major isolate among nonalbicans Candida followed by Candida glabrata which is similar

\begin{tabular}{llcc}
\multicolumn{3}{l}{ Table 1: Distribution of collected numbers of } \\
samples among the clinical specimens \\
\hline S.no. & Clinical specimens & Numbers & Percentage (\%) \\
\hline 1 & Sputum & 17 & 28.81 \\
2 & Vaginal swab & 16 & 27.11 \\
3 & Urine & 9 & 15.25 \\
4 & Wound swab & 4 & 6.67 \\
5 & Long line tip & 3 & 5.08 \\
6 & Cervical swab & 2 & 3.38 \\
7 & Broncho-alveolar lavage & 2 & 3.38 \\
8 & Stool & 2 & 3.38 \\
9 & Sub hepatic fluid & 1 & 1.69 \\
10 & Oral tissue & 1 & 1.69 \\
11 & Skin scrapping & 1 & 1.69 \\
12 & Nail clipping & 1 & 1.69 \\
Total & 12 & 59 & $100 \%$ \\
\hline
\end{tabular}

to our study. ${ }^{21}$ Various study in the past has shown the increasing numbers of non-albicans Candida species were

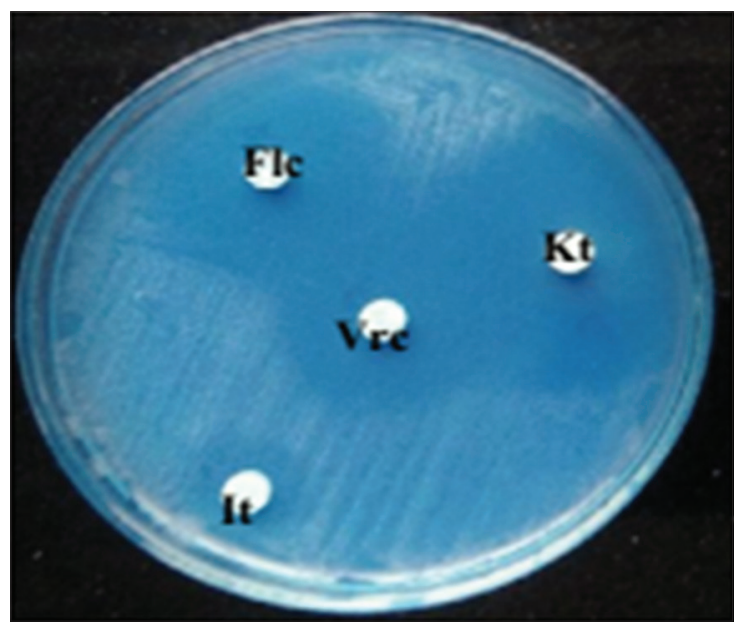

Figure 1: Sensitive to Fluconazole, Voriconazole, Ketoconazole, Resistant to Itraconazole

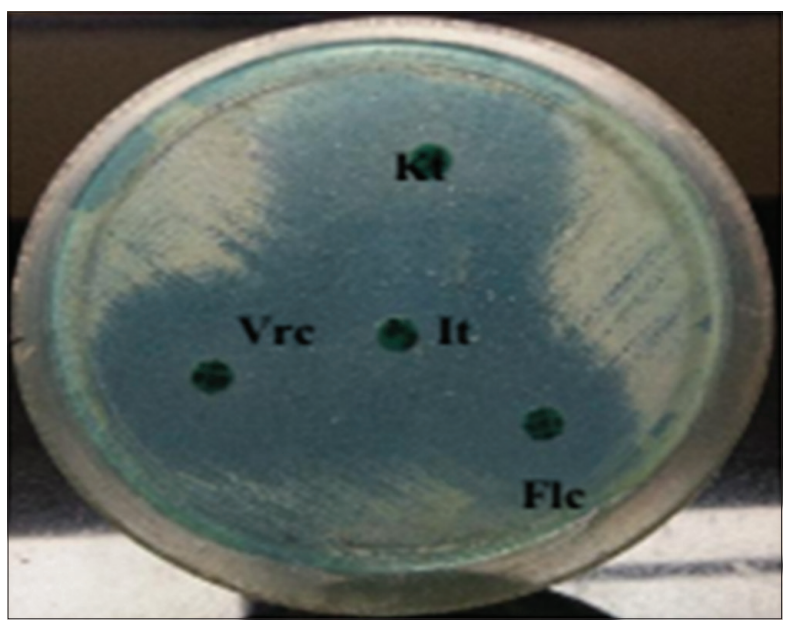

Figure 2: Susceptible to Fluconazole, Voriconazole, Ketoconazole, Itraconazole

\section{Table 2: Antifungal susceptibility pattern of all the isolated Candida species}

\begin{tabular}{|c|c|c|c|c|}
\hline Species of candida & $\begin{array}{c}\text { Fluconazole } \\
\mathbf{S}\end{array}$ & $\begin{array}{c}\text { Voriconazole } \\
\mathrm{S}\end{array}$ & $\begin{array}{c}\text { Ketoconazole } \\
\mathrm{S}\end{array}$ & $\begin{array}{c}\text { Itraconazole } \\
\mathrm{S}\end{array}$ \\
\hline C. tropicalis & $\begin{array}{c}31 \\
7561 \%\end{array}$ & 37 & 28 & 22 \\
\hline$(n=41)$ & $75.61 \%$ & $90.24 \%$ & $68.29 \%$ & $53.66 \%$ \\
\hline C. glabrata & 3 & 3 & 2 & 1 \\
\hline$(n=5)$ & $60 \%$ & $60 \%$ & $40 \%$ & $20 \%$ \\
\hline C. parapsilosis & 4 & 4 & 3 & 2 \\
\hline$(n=4)$ & $100 \%$ & $100 \%$ & $75 \%$ & $50 \%$ \\
\hline C. Iusitaniae & 2 & 3 & 3 & 2 \\
\hline$(n=4)$ & $50 \%$ & $75 \%$ & $75 \%$ & $50 \%$ \\
\hline C. guilliermondii & 2 & 2 & 2 & 2 \\
\hline$(n=2)$ & $100 \%$ & $100 \%$ & $100 \%$ & $100 \%$ \\
\hline C. kefyr & 1 & 2 & 1 & 0 \\
\hline$(n=2)$ & $50 \%$ & $100 \%$ & $50 \%$ & $0.00 \%$ \\
\hline C. krusei & 1 & 1 & 1 & 1 \\
\hline$(n=1)$ & $100 \%$ & $100 \%$ & $100 \%$ & $100 \%$ \\
\hline TOTAL & 44 & 52 & 40 & 30 \\
\hline PRECENTAGE & $74.57 \%$ & $88.13 \%$ & $67.79 \%$ & $50.84 \%$ \\
\hline
\end{tabular}




\begin{tabular}{|c|c|c|c|}
\hline $\begin{array}{l}\text { Antifungal } \\
\text { agents }\end{array}$ & Concentration & $\begin{array}{c}\text { Zone diameter } \\
\text { inmm }\end{array}$ & $\begin{array}{c}\text { Quality } \\
\text { control limits }\end{array}$ \\
\hline S R & $\begin{array}{c}\text { C. parapsilosis } \\
\text { ATCC22019 }\end{array}$ & & \\
\hline Fluconazole & $25 \mu \mathrm{g}$ & $\geq 19 \leq 14$ & $22-33$ \\
\hline Voriconazole & $1 \mu \mathrm{g}$ & $\geq 17 \leq 13$ & $28-37$ \\
\hline Ketoconazole & $15 \mu \mathrm{g}$ & $\geq 28 \leq 20$ & $20-26$ \\
\hline Itraconazole & $10 \mu \mathrm{g}$ & $\geq 23 \leq 13$ & $26-35$ \\
\hline
\end{tabular}

isolated which is comparable to our study, moreover these findings suggest that the non-albicans Candida species taking over Candida albicans day by day as an important pathogens since past 2-3 decades.Non albicans Candida has got direct impact on choosing the empirical antifungal treatment. ${ }^{18}$

Other non-albicans Candida isolated in our study were, Candida glabrata, Candida lusitaniae, Candida parapsilosis, Candida guilliermondii, Candida kefyr, Candida krusei. It is proved in many studies that distribution of Candida species follows geographic distribution. Thus our study adds-up to the observation of, Candida tropicalis, being prevalent in causing Candidiasis, in Eastern Asia.

In our study, isolates showed highest sensitivity to Voriconazole whereas were least sensitive to Itraconazole by disk diffusion method. Of all the isolated Candida species, sensitivity for Voriconazole was $88.13 \%$ (52) followed by Fluconazole 44(74.57\%), ketoconazole 40(67.79\%) and the least sensitivity was against Itraconazole 30(50.84\%). Candida guilliermondii and Candida krusei, both being single isolates were sensitive to all the tested antifungals.

In a study done by Jangla $e t$ al ${ }^{19}$ Candida tropicalis and Candida parapsilosis were $100 \%$ sensitive to Fluconazole and Voriconazole. Sebastian. A et al ${ }^{20}$ have shown $62.2 \%$, $58.8 \%, 47 \%$ sensitivity against Fluconazole, Itraconazole, Ketoconazole respectively which is nearly similar to that our study which shows $74.57 \%$ to fluconazole, $67.79 \%$ to Ketoconazole, $50.84 \%$ to itraconazole respectively. ${ }^{19,20}$

Our study showed Voriconazole is an effective drug $52(88.13 \%)$ where as $100 \%$ sensitive to Voriconazole was found in a similar study done by Deepthi.T $e t$ al,$^{21}$ $60 \%$ by Dharwad. S et al, ${ }^{22} 83 \%$ by Shafi FT et a ${ }^{23}$ respectively. ${ }^{21-23}$ Though Voriconazole is found to be effective in the study, the observation has to be practiced with a guard. The results need to be validated by another study where in clinical correlation would be appropriate. In our study Candida glabrata had shown the highest level of resistant against Itraconazole followed by Ketoconazole whereas Candida tropicalis had shown the highest level of resistant to Itraconazole among all the tested antifungal agents. Candida kefyr showed 100\% resistant to Itraconazole.

In our study, among various clinical specimens increasing numbers of Candida isolates were isolated from sputum samples followed by vaginal swabs and urine samples whereas the least were isolated from sub hepatic fluid, oral tissue respectively.Several studies in the past indicates the increasing growing rates of non-albicans Candida over Candida albicans is an essential clue to proper monitoring in the distribution of antifungal agents for the pathogenic Candida species. ${ }^{24}$ Candida was isolated from a neonatal case repeatedly twice. The baby had diarrhoea and was on broad spectrum antibiotics thus the isolate was included in the study. The isolate was C. tropicalis. Candida is known to cause antibiotic induced diarrhea. ${ }^{25}$

\section{CONCLUSION}

Candida non-albicans species are being common isolates from cases of Candidiasis. Candida tropicalis is the predominant isolate, followed by Candida glabrata, Candida lusitaniae, Candida parapsilosis, Candida guilliermondii, Candida kefyr and Candida krusei. Most of the isolates were sensitive to Voricanazole and resistant to Itraconazole. Resistance was most commonly seen in Candida glabrata, Candida kefyr had shown 100\% resistant against Itraconazole. Thus the study emphasizes the need for speciation of Candida isolates and recommends antifungal susceptibility for all the clinical isolates. To identify various isolates of Candida to their species level along antifungal sensitivity pattern is clinically significant for the appropriate choice of antifungal therapy.

\section{ACKNOWLEDGEMENTS}

We acknowledge for all the participants of the study.

\section{ETHICAL APPROVAL}

The study was approved by theInstitutional Ethics Committee of Jawaharlal NehruMedical College, KLE Academy Higher Education andResearch, Karnataka, India.

\section{REFERENCES}

1. Mujika MT, Finquelievich JL, Jewtu chowicz $V$ andlovannitti CA. Prevalence of Candida albicans and Candida non-albicans in clinical samples during 1999-2001. Rev Argent Microbiol 2004;36:107-112.

2. Mohandas $V$ and Ballal M. Distribution of Candida Species in Different Clinical Samples and Their Virulence: Biofilm Formation, Proteinase and Phospholipase Production: A Study on Hospitalized Patients in Southern India. J Glob Infect Dis 2011; 3(1): 4-8.

https:doi.org/10.4103/0974-777X.77288 
3. Bhavana C Nagarathnamma andAmbica R. Speciation of Candida and Antifungal Susceptibility Testing From Clinical Specimens In A Tertiary Care Hospital, Bangalore. International Journal of Current Research 2017;9(01):45832-45836.

4. Devadas SM, Ballal M, Prakash PY, Hande MH, Bhat GV and Mohandas V. Auxanographic carbohydrate assimilation method for large scale yeast identification. Journal of Clinical and Diagnostic Research 2017;11(4): DC01-DC03.

https:doi.org/10.7860/JCDR/2017/25967.9653

5. Chandra J, Text Book of Medical Mycology $4^{\text {th }}$ Edition, Jaypee Brothers Medical Publishers (P) Ltd, 2018, Antifungal Susceptibility Testing, Appendix D;874-875.

6. Rudrappa PT, Chandrashekar SC and Suman MN. Speciation of Candida Isolates from Clinical Samples by using Conventional and Chromagar Method. Int J Curr Microbiol App Sci 2018; 7(3):2663.

https://doi.org/10.20546/ijcmas.2018.703.307

7. Anaissie Elias J, McGinnis MR, Pfaller MA. Clinical Mycology $1^{\text {st }}$ Edition, Churchill Livingstone 2003, Candida 8; 195-225.

8. Larone HD. Medically Important Fungi, A Guide To Identification $4^{\text {th }}$ Edition, ASM Press 1752 M Street N.W Washington DC 20036-2904 USA, 2002, Media; 325-335.

9. Nadeem SG, Hakim ST and Kazmi SU. Use of Chromagar Candida for the presumptive identification of Candida Species Directly from Clinical Specimens in Resource-Limited Settings. Libyan Journal of Medicine2010;5(1):2144.

https://doi.org/10.3402/ljm.v5i0.2144

10. Rana A, Sharma A and Pandey G. Diagnostic Value of sputum Gram's stain and sputum Culture in Lower Respiratory Tract infection. International Journal of Current Microbiology and Applied Sciences 2017; 6(7):4310-4314.

https://doi.org/10.3389/fmed.2019.00064

11. Kulshrestha S, Soni P, Parihra RS, Khatri PK and Soni LK. AbnormalVaginal Discharge: Comparison of Clinical and Microbiological criteria for The Diagnosis of Bacterial Vaginosis. International Journal of Biomedical and Medical Research2015(3):5090-5094.

12. Chandra J, Text Book of Medical Mycology $4^{\text {th }}$ Edition, Jaypee Brothers Medical Publishers (P) Ltd, 2018, Candiadiasis20;401-423.

13. Golia S, Reddy KM, Karjigi KS and Hittinahalli V. Speciation of Candida using chromogenic and cornmeal agar with determination of fluconazole sensitivity. Al Ameen J Med Sci 2013;6(2):163-166.

https://doi.org/10.18203/2320-6012.ijrms20173554

14. Vignesh Kanna B, Amar Kumar G, Swapna M and Joshy M. Easow. Isolation and Identification of Candida Species from Various Clinical Samples in a tertiary Care Hospital. International Journal of Research in Medical Sciences 2017; 5(8): 3520-3522 http://dx.doi.org/10.18203/2320-6012.jirms20173554
15. HiMedia Laboratories Pvt. Ltd, A-516,Via Vadhani Ind. Est, Mueller Hinton Agar, 2\% Glucose with Methylene blue2011;M1825.

16. CLSI. Performance Standards for Antifungal Susceptibility Testing of Yeasts. 1st ed. CLSI supplement M60. Wayne, PA: Clinical and Laboratory Institute;2017.

17. Singh R, Verma RK, Kumari S, Singh A and Singh DP. Rapid Identification and Susceptibility Pattern of Various Candida Isolates from Different Clinical specimens in a Tertiary Care Hospital in Western Uttar Pradesh. International Journal of Research in Medical Sciences 2017; 5. 3466. https://doi.org/10.18203/2320-6012.ijrms20173542

18. Khadka S, Sherchand JB, Pokhrel BM, Parajuli K, Mishra SK, Sharma S, et al. Isolation, speciation and antifungal susceptibility testing of Candida isolates from various clinical specimens at a tertiary care hospital, Nepal. BMC ResearchNotes 2017; 10(1):218.

https://doi.org/10.1186/s13104-017-2547-3

19. Jangla SM, Naidu R and Patel SC. Speciation and Antifungal Susceptibility Testing of Candida Isolates in Various Clinical Samples in a Tertiary Care Hospital in Mumbai. International Journal of Biomedical Research 2018; 9(3): 106-111. https://doi.org/10.7439/ijbr.v9i3.4678

20. Badiee P, Choopanizadeh M, Moghadam AG, Nasab AH, Jafarian $H$, Shamsizadeh $A$, et al. Antifungal Susceptibility Patterns of Colonized Candida Species Isolates from Immunocompromised Paediatric Patients in five University Hospitals. Iranian Journal of Microbiology 2017;9(6):363. https://doi.org/10.1186/s12879-017-2825-7

21. Deepthi T, Pradeep MSS and Setty CR. Speciation, Detection of Virulence Factors and Antifungal Susceptibility Testing of Candida Isolates in a Tertiary Care Hospital. IOSR Journal of Dental and Medical Sciences (IOSR-JDMS) 2016; 15(10) Ver. VIII: $20-23$ https://doi.org/10.9790/0853-1510082023

22. Dharwad S and Saldanha DR. Species Identification of Candida Isolates in Various Clinical Specimens with their Antifungal Susceptibility Patterns. Journal of Clinical and Diagnostic Research 2012;5(6):1177-1181.

23. Shafi FT, Padmaraj SR and Mullessery NP. Species distribution and antifungal susceptibility pattern of Candida causing oral candidiasis among hospitalized patients. Archives of Medicine and Health Sciences 2015;3(2):247. https://doi.org/10.4103/2321-4848.171914

24. Badiee $P$ and Alborzi A. Susceptibility of Clinical Candida Species Isolates to Antifungal Agents by E-test, Southern Iran: A five year Study. Iranian Journal of Microbiology 2011;3(4):183.

25. Krause R, Schwab E, Bachhiesl D, Daxböck F, Wenisch C, Krejs GJ, et al. Role of Candida in antibiotic-associated diarrhea. Journal of Infectious Diseases 2001; 184:1065-1069. https://doi.org/10.1086/323550

\footnotetext{
Authors Contribution:

LS- Concept and design of the study, data collection, analyzed and interpreted, reviewed the literature, manuscript preparation and critical revision of the manuscript; SUH-Concept, and review of literature and helped in preparing first draft of manuscript; BB- Prepared first draft of manuscript and critical revision of the manuscript; KP- Conceptualized study, literature search, statistically analyzed and interpreted, prepared first, draft of manuscript and critical revision of the manuscript and data collection.

Work attributed to:

Department of Microbiology, KLE Academy of Higher Education and Research, Jawaharlal Nehru Medical College, Belagavi, Karnataka, India.

Orcid ID:

Lokjan Singh - (10 https://orcid.org/0000-0002-3293-3900

Source of support: None, Conflicts of Interest: None
} 